\title{
The Becoming of the Complex Socium: New Causes of Deviance and Crime
}

\author{
Sergey A. Kravchenko*
}

Department of Sociology, MGIMO-University, 76, Vernadsky Prospect, 119454, Moscow, Russia

\begin{abstract}
This article focuses on the factors that influence the becoming of the complex socium. The author considers, in his opinion, the most characteristic parameters of the complex socium that is developing in the context of the 'arrow of time'. He asserts that the becoming of the complex socium brings unintended consequences producing new causes of deviance and crime. Under these conditions he argues for the humanistic turn in sociology, based on non-linear and humanistic sociological imagination, and humanistic praxis.
\end{abstract}

Keywords: Complex socium, reflexivity, dehumanization, deviance.

\section{INTRODUCTION}

According to P. Sztompka, President (2002-2006) of the World Sociological Association, the modern world is in a state of becoming that occurs in the context of related social and cultural traumas. He proposed the theory of social becoming, aimed at the analysis of the "society in action". One can really witness the becoming of the complex socium and I shall consider the most characteristic parameters of the complex socium that is developing in the context of the "arrow of time" - the effect founded by I. Prigogine. According to it all the matter (this concerns as material as social worlds) is being developed increasingly quicker and becomes more and more complex, including points of bifurcation $^{2}$. At the same time the complex socium produces new dehumanized effects and new causes of deviance and crime, but they are not fatal.

\section{COMPLEX SOCIUM, REFLEXIVITY AND SOCIAL TRAUMA}

The complex socium makes cities crime-infested and disorderly places. According to the founders of the social disorganization theory of crime, increasingly large numbers of people in rapidly growing places populated by newcomers and strangers are more likely to commit deviant or criminal acts $^{3}$. Nowadays the complex socium acquires a new quality - it is becoming

*Address corresponding to this author at the Department of Sociology, MGIMO-University, 76, Vernadsky Prospect, 119454, Moscow, Russia; Tel: + 749543494 26; Fax: + 749543494 26; E-mail: sociol7@yandex.ru

\footnotetext{
${ }^{1}$ Sztompka, Piotr. 1991. Society in Action: A Theory of Social Becoming. Cambridge: Polity Press.

${ }^{2}$ Prigogine, llya. 1997. The End of Certainty. New York: Free Press.

${ }^{3}$ Park, Robert. 1952. Human Communities: the City and Human Ecology. Glencoe, IL: Free Press; Shaw, Clifford, R. 1952. Brothers in Crime. Philadelphia: Albert Saifer.
}

more and more reflexive. The social actors (both collective and individual) are increasingly getting out of the structural constraints of social systems that previously quite rigidly determined their behavioural capabilities. People become even more relatively free to violate norms. They take on a fundamentally new functional quality - the agency as the human collective capacity for the reflexivity, creative self-transformation that complicates the process of the development of the socium and transforms it through the inclusion of both intentional and unintended consequences. Now the nature of their functional behaviour is practically limited only, according to P. Bourdieu, by their habitus ${ }^{4}$ or, as A. Giddens considers, by the previous social practices $^{5}$. Theses are inner constraints that do not function properly when the external structural constraints are weakening. I argue this is one of the new causes of deviance and crime.

The increasing reflexivity of the socium and its unintended consequences was the central problem of the $8^{\text {th }}$ European Sociological Association Conference (2007, Glasgow). Of particular interest was the address by Margaret $\mathrm{S}$. Archer, dedicated to "the new reflexive imperative and transformations of civil society". She asserts that "the progressive effect of modernity, as morphogenesis began its unsynchronised emergence in structure and culture, was one that entailed increased reflexivity... for the first time in human history, the reflexive imperative applies to all... Individual life worlds are no longer amenable to orchestration by 'habitus', but neither is public life at the

\footnotetext{
${ }^{4}$ Bourdieu, Pier. 1990. In Other Words: Essays towards a Reflexive Sociology. Stanford, CA: Stanford University Press.

${ }^{5}$ Giddens, Antony. 1990. The Consequences of Modernity. Cambridge: Polity Press.
} 
capricious mercy of individualized serial selfreinvention"

The influence of the reflexivity is ambivalent. On the one hand, the variety of the behaviour patterns increases greatly and so does man's freedom. But on the other hand, this freedom is not always for the good, may be the cause for deviant and criminal behaviour. The famous British sociologist Zygmunt Bauman pays attention to the fact that some human reflexivity lacks its proper humane characteristics. In the essay "As the birds do" he metaphorically compares human reflexivity with the birds' one. He argues that 'Twitter' is what birds produce when they tweet. Tweeting plays two roles in the life of birds: it allows them to keep in touch with each other, and to prevent other birds from transgressing on the territory they've made their own. Human Twitter that appeared only in 2006 practically has the same functions, presupposing simple questions and compact and shot answers - no longer than 140 characters. The result is as follows. "Once face-to-face contact is replaced by a screen-to-screen variety, Bauman writes, - it is the surfaces that come in touch. Courtesy of Twitter, 'surfing', the preferred means of locomotion in our hurried life of instantly born and instantly vanishing opportunities, has finally caught up with interhuman communication. What has suffered as a result is the intimacy, the depth and the durability of human intercourse and human bonds"7.

I'll also mark four more problems of dehumanization concerning the reflexivity in the complex socium: 1 ) the decline of human relations, lack of attachments facilitates the violation of norms; 2) modern actors possess tremendous knowledge which is the 'force' of change, but without a humanistic orientation of man's reflexivity, without the proper humane ethics it is opposed to the civil society and even destroys it; 3 ) there is yet little realization that we are dealing with the management of the complex social systems. Simple pragmatic solutions of social problems based on force can't be effective nowadays, especially for the development of humane characteristics of the socium; 4) the correlations among causes and crimes become non-linear mainly due to the facts that social traumas

\footnotetext{
${ }^{6}$ Archer, Margaret. 2007. From High Modernity to Nascent Globalization: The New Reflexive Imperative and Transformations of Civil Society. In: The $8^{\text {th }}$ European Sociological Association Conference. Conflict, Citizenship and Civil Society. Programme. $3^{\text {rd }}-6^{\text {th }}$ September 2007. Glasgow Caledonian University. Pp. 36-37.

${ }^{7}$ Bauman, Z. 2011. 44 Letters from Liquid Modern World. Cambridge: Polity Press. Pp. 18, 19
}

and points of bifurcation have come into our every day life.

P. Sztompka argues that traumas are, in fact, the attributes of social becoming. Hence a new discourse is born - the discourse of trauma dealing "with the problem of negative, dysfunctional, adverse effects that major social change may leave in its wake, the 'trauma of change' inflicted on the 'body' of a changing society" "Trauma would indicate a specific pathology of agency... understood as a complex, synthetic quality of human collectivity allowing for its creative selftransformation"9. According to him, traumas lead to the normative disorientation that is expressed in splits, ambivalences, clashes within a culture. A new alien culture comes to people who have to do with the sudden and unexpected novelty that undermines their everyday life and the traditional culture. "A traumatic sequence is started only when such maladjustments, tensions, and clashes are perceived and experienced as problems, as something troubling or painful that demands healing" ${ }^{\prime 10}$.

Traumas are both objective and subjective. Its objective side is potentially expressed in the growth of unemployment, poverty, deviant and crime behaviour, and degradation of status. Here are some subjective characteristic symptoms of the trauma: mistrust in the institutions of power as the political elite is effected by corruption; a gloomy outlook for the future, reflected in the fears and anxieties; nostalgia for the past; political apathy, the manifestations of civil initiatives are rare.

The traumatic event as a subjective cultural construction was specially studied by J.C. Alexander. From the standpoint of the methodology of his cultural sociology the social trauma is not an actual social fact, but something of the status of evil as the result of the coding, narrating its meaning through the prism of certain cultural values and norms. "For a traumatic event to have the status of evil is a matter of its becoming evil, - he writes. - It is a matter of how the trauma is known, how it is coded" "11. Originally coding is performed by means of the binary opposition, which represents the relationship in a socially and culturally constructed systems in which the sign acquires its

\footnotetext{
${ }^{8}$ Sztompka, P. 2000. Cultural Trauma. The Other Face of Social Change // European Journal of Social Theory, 2000. № 3(4). P. 450.

${ }^{9}$ Later citation (Sztompka, P. 2000: 452).

${ }^{10}$ Later citation (Sztompka, P. 2000: 455).

${ }^{11}$ Alexander, Jeffrey C. 2003. The Meanings of Social Life. A Cultural Sociology. N.Y.: Oxford University Press. P. 31.
} 
meaning only in context with the other sign, located in the opposition to it (good - evil, liberal democracy democratic repression, sacred - profane etc.). The sociologist shows the process of coding of the phenomenon, its conversion into a trauma on the example of the Holocaust, that represents an 'ontological evil'. It is the product of cultural work that has become a symbol of human suffering and moral evil associated with ethnic and racial hatred, which is used for typing new mass violence against the people. "If the Allies had not won the war, the 'Holocaust' would never have been discovered... It was, in other words, precisely and only because the means of symbolic production were not controlled by a victorious postwar Nazi regime, or even by a triumphant communist one, that the mass killing could be called the Holocaust and coded as evil"12. It is essential that the phenomena are coded as traumatic, if they violate the collective identity of people, thereby creating a cultural crisis. "For traumas to emerge at the level of collectivity, social crises must become cultural crises, - Alexander argues. - Events are one thing, presentations of these events quite another. Trauma is not the result of a group experiencing pain. It is the result of this acute discomfort entering into the core of the collectivity's sense of its own identity"13. For instance, the governments may be unable to provide a low level of criminality for their citizens, but it is not traumatic for the members of society, if it does not affect their collective identity ${ }^{14}$.

The essence of trauma also depends on its narrative and people's history. According to $\mathrm{C}$. Caruth, unconscious emotions impose on traumatic experiences $^{15}$.

Thus, the social becoming of a complex society that is associated with trauma, in principle, can not but affect the interests of the majority producing objective and subjective dehumanized effects. Moreover, traumas may be caused by the manipulation of social consciousness through the appropriate signification of phenomena. As a result traumas increase social vulnerability by provoking deviant and criminal behaviour due to undermining the collectivity's sense of the previous identity.

\footnotetext{
${ }^{12}$ Later citation (Alexander, Jeffrey C. 2003: 32-33).

${ }^{13}$ Later citation (Alexander, Jeffrey C. 2003: 93).

${ }^{14} \mathrm{Neal}$, Arthur. 1998. National Trauma and Collective Memory. Armonk, NY: Sharpe; Eyerman, Ron. 2001. Cultural Trauma: Slavery and the Formation of African American Identity. New York: Cambridge University Press.

${ }^{15}$ Caruth, Cathy, ed. 1995. Trauma: Explorations in Memory. Baltimore: Johns Hopkins University Press.
}

THE UNINTENDED CONSEQUENCES, PARADOXES AND SIDE-EFFECTS

Traumas, uncertainties and vulnerabilities that came into our life do not presuppose a pure chaos at all, but rather non-linear developing social systems that manifest a new social order. Thus, I. Prigogine speaks about emergent, dynamic and self-organizing systems interacting in ways that heavily influence the probabilities of later events ${ }^{16}$. "The complex systems world, - John Urry writes, - is a world of avalanches, of founder effects, self-restoring patterns, apparently stable regimes that suddenly collapse, punctuated equilibria, 'butterfly effects' and thresholds as systems tip from one state to another" ${ }^{\prime 17}$. Order and chaos, he notes, are in a certain state of balance "where the components are neither fully locked into place but yet do not dissolve into anarchy. They are 'on the edge of chaos"'18.

This is a fundamentally new perspective on the nature of the social order and the factors to provide it. According to T. Parsons, the hierarchy of values and norms that embraces all the levels of society involves the mechanisms that are in a case of any deviations effectively restore the social equilibrium ${ }^{19}$. Hence, now the situation is changing: under the conditions of the complexity the efforts to restore the social order almost always generate further unintended consequences pushing the socium away from the social equilibrium. Moreover, the social order in any country depends on the situations in other countries within the complexity of transnational relations. The same one can say about the situation with criminality. Thus, the current terrorist and criminal turbulence in Africa concerns the whole world. Waves of it in the form of unintended consequences (the increase of illegal migration, new problems with food and water supply etc.) affect the functioning of the international law.

In a complex society the consequences of some political actions, that at first sight would seem insignificant, appear non-linearly in time and space producing dramatic new effects as sudden changes in the social order. Chaos theory, in particular, rejects the common-sense view that only large changes can have big consequences. "With non-linearity there is no

\footnotetext{
${ }^{16}$ Later citation (Prigogine, llya. 1997: 35).

${ }^{17}$ Urry, John. 2005. The Complexities of the Global // Theory, Culture \& Society, 2005. Vol. 22 (5). P. 237.

${ }^{18}$ Later citation (Urry, John. 2005: 238)

${ }^{19}$ Parsons, Tolkott. 1960. Structure and Process in Modern Societies. New York: Free Press.
} 
consistent relationship between causes and effects. The same 'cause' can in specific circumstances produce quite different kinds of effect" ${ }^{20}$.

Humans have to adapt to the becoming of the complex social order that produces new challenges to the social consciousness. In recent times, the social consciousness was rather homogeneous. Nowadays, the social consciousness as a complex system is characterized by temporal dyschronization: in one and the same social space there coexist people actually living in different tempoworlds and, correspondingly, they have very different consciousness. Therefore, the life-worlds of some social groups may belong to one social time, and others - to quite another that inevitably leads to the normative dispersion of the regulatory and thus to deviant and criminal acts.

The complex socium manifests itself in the open society. Karl Popper has shown that the historical development of the human civilization is on the transition from a closed society that heavily regulated all the aspects of people's life to the open one that creates the conditions for the development of individual freedoms ${ }^{21}$. In essence, the ideologists of liberalism consider the open society as a 'universal' ideal for all mankind.

Since then, many countries including Russia have become truly open societies, and regardless of the people's desire move to a greater openness of the open society. However, this process is already causing not only a real enthusiasm for the emergence of freedoms, but also social anxiety and, according to Z. Bauman, "liquid fear"22 associated with coming into our life the instability, uncertainty, vulnerability and new dehumanized consequences. The Europeans were among the first to realize the uncontrollable side-effects of the open society. After a series of democratic revolutions in Europe and Russia, Francis Fukuyama, in fact, has proclaimed the victory of the ideals of liberalism ${ }^{23}$ worldwide including those of the open society. But the quantum leap to the openness of society almost immediately led to the paradox: this openness has sharply aggravated the problem of "ageing" of the existing European societies, their institutions, ideals and values resulting in the

\footnotetext{
${ }^{20}$ Later citation (Urry, John. 2005: 238).

${ }^{21}$ Popper, Karl. 1950. The Open Society and its Enemies. London: Routledge and Kegan Paul.

${ }^{22}$ Bauman, Zygmunt. 2006. Liquid Fear. Cambridge: Polity Press.

${ }^{23}$ Fukuyama, Francis. 1992. The End of History and the Last Man. N.Y.: Free Press.
}

appearance of new threats and fears. Z. Bauman writes about the change of the liberal ideals: "The specter of social degradation against which the social state swore to insure its citizens is being replaced in the political formula of the 'personal safety state' by threats of a paedophile on the loose, of a serial killer, an obtrusive beggar, a mugger, stalker, poisoner, terrorist, or better still by all such threats rolled into one in the figure of an illegal immigrant, against whom the modern state in its most recent avatar promises to defend its subjects" ${ }^{24}$.

Besides, openness presupposes the possibility of acceptance of all the circulating values in the world, including criminal ones. For instance, in modern Russia there appeared quite new forms of deviance and crime that do not have cultural roots in its history. Among them: drug abuse, slave-trade, kidnapping, the trade of human organs, gambling, game addiction, property crimes, Nazism, racism and terrorism that make quite a new problem dealing with risk-producers and riskconsumers $^{25}$.

Another ambivalence of the open society is the formation of a paradoxical synthesis of a single global world community and unprecedented dehumanized segregations. Bauman points out that the flip side of global processes, in particular, of global tourism is the emergence of new enclaves, whose representatives are 'untouchables', 'unthinkables' and even 'unimaginables'26. Certainly, these non-people selfreproduce 'community ghettos' that cannot communicate with 'normal' societies.

In complex socium the speed of social change does not only reduce the social distance and time for the people living in different regions of the world, but the humanity has come to the threshold of actual human capacity of reflection transient events that is to act adequately, rationally, and most importantly - to make decisions based on humane purposes. The part of short-lived socium constantly increases while the share of long-lived one decreases. It concerns the life time for the proper functioning of institutional structures, reference groups, ideals, values, authorities, knowledge, making the rapidly changing socium humanly alien.

\footnotetext{
${ }^{24}$ Bauman, Zygmunt. 2009. Liquid Times. Living in an Age of Uncertainty. Cambridge: Polity Press. P. 15.

${ }^{25}$ Yanitsky, O.N. 2010. Russian Environmentalism. The Yanitsky Reader. Moscow: Taus.

${ }^{26}$ Later citation (Bauman, Zygmunt. 2009: 45).
} 
If some social groups cannot cope with the increasing speed of change, if they do not have enough time to be reflexive on the consequences of changes, there may appear new social upheavals, the reason for which is temporal dyschronization. The increasing of the speed, in particular, leads to a blurring of references: people do not have time to adequately and humanely reflect on the consequences of scientific and technological innovations. Under new conditions their behaviour becomes to be considered as "deviant" though recently it was quite "normal".

Simulations and simulacra have come into our lives which implies a symbolic, coded way of displaying the realities. The complexity of the virtual reality is manifested in the fact that the distinctions between the real and the imagined disappear. For F. Jameson all the postmodern things are simulacra that sweep away the habitual realities: "the past itself has disappeared"27. According to J. Baudrillard, we witness the movement toward the universal "establishment of an abstract and model system of signs" ${ }^{\prime 2}$ that he calls 'hyperreality'. Modern people, he believes, are dealing with the imaginary representations of the reality, with the hyperreality. The increasing proliferation of simulacra puts the 'end' of the social reality.

The side-effects of the hyperreality are new forms of dehumanization. Thus, for Baudrillard, the public opinion does not reflect the reality but hyperreality: respondents do not express their own opinion - they reproduce what has previously been established as a system of symbols by the media. According to him, the practical reality referents disappear and so does the truth, they are replaced by simulacra. How does it influence the deviance and crime? In my opinion this leads to the increasing gap between the victimization as it is expressed in the public opinion and the data based on official police statistics. The trust to the police depends not so much on its real functionality but on the corresponding simulacra. In the post-reform Russian society in 2010 only $21 \%$ of its population (surveys of the public opinion conducted by Institute of Sociology, Russian academy of science) trusted the police ${ }^{29}$ so many people fail to report that they have been victimized to the police, but some will do so if asked directly about it.

\footnotetext{
${ }^{27}$ Jameson, John F. 1991. Postmodernism, or, The Cultural Logic of Late Capitalism. Durham: Duke University Press. P. 309.

${ }^{28}$ Baudrillard, Jean. 1983. Simulations. New York: Semiotext(e). P. 65.

${ }^{29}$ Gorshkov, Mikhail K. 2011. Russian Society as it is (Experience of Sociological Diagnostics). Moscow: Russian Academy of Sciences. Institute of Sociology. P. 18.
}

A complex socium is characterized by increasingly complex risks. The risk is a dynamic phenomenon, influenced by social and cultural dynamics of a nonlinear, self-organized society.

In a traditionally society the risk was interpreted as a courageous though deviant act connected with a humane choice of some individuals undertaken for the sake of achieving the socially important results. But there is no direct correlation between the risk and humanism in a long run context of the social development. Over time there appeared risks of desocialization and dehumanization of socium and the human capital. Nowadays within the concept of 'world risk society' U. Beck develops a whole series of conceptual innovations. Among them are three characteristic features of global risks: 1 . Delocalization: their causes and consequences are not limited to one geographical location. 2. Incalculability: their consequences are in principle incalculable. 3. Noncompensatability: if climate change is irrevocable, if human genetics makes possible irreversible interventions in human existence, then it's too late ${ }^{30}$. These risks are side-effects of globalization. I think the same characteristic features are typical to some global crimes: terrorist activities, as well as war crimes, criminal experiments on cloning an "ideal" man etc. are becoming delocalized, their consequences are incalculable and cannot be compensated.

\section{HUMANISTIC TURN}

I argue that in order to deal effectively with the realities of the complex socium in general and with new causes of deviance and crime in particular the synthesis of the natural sciences, social science and humanities is needed. Such integration, on the one hand, would take into maximum consideration the socio-cultural dynamics, all sorts of dispersion and vulnerability of society and, on the other hand, the time has come to search for new forms of humanism, including the humanistic orientation of any research that is becoming an ethical imperative of the global community of nations.

We need 'humanistic turn' in sociology that implies both a non-linear and humanistic sociological imagination, and humanistic praxis. Our starting premise lies in the fact that the non-linear humanistic sociological imagination should in principle be based

\footnotetext{
${ }^{30}$ Beck, Ulrich. 2010. World at Risk. Cambridge: Polity Press. P. 52.
} 
on the adequate and deeper understanding of ambivalent realities of the complex socium. All the existing types of sociological imagination worked out by C. Wright Mills ${ }^{31}$, P. Sztompka ${ }^{32}$, S. Fuller ${ }^{33}$, U. Beck ${ }^{34}$ and other scholars are very significant in the scientific sense, because in one or another way they efficiently reflect the important aspects of increasingly complex socium. But for all their undoubted merits each of these types of sociological imagination focuses, in my opinion, on rather specific aspects of the complex socium and what is more important - lacks the problem of humanistic orientation of its agency in general.

By humanistic praxis I understand the humane creative activity the main aim of which is to preserve the human capital of all the generations and to maintain the balance between scientific innovations and key environmental processes. These intensions are not a utopia under the conditions of the complex socium that gives new opportunities to produce powerful knowledge of the humane type. In this case, the notion 'tremendous knowledge' should be rediscoved: it should mean not much knowledge, but humane knowledge. The same can be said about the agency as the human collective capacity for the reflexivity - it should acquire the characteristics of humane reflexivity.

\footnotetext{
${ }^{31}$ Mills, C.W. 1959. The Sociological Imagination. New York: Oxford University Press.

${ }^{32}$ Sztompka, P. 1991. Society in Action: A Theory of Social Becoming. Cambridge: Polity Press.

${ }^{33}$ Fuller, S. 2008. The New Sociological Imagination. London: Sage Publications.

${ }^{34}$ Beck, U. 2007. Risk Society Revisited: Theory, Politics and Research Programmes // The Risk Society and Beyond / B. Adam, U. Beck, J. van Loon (ed.). L.: Sage Publication.
}

\section{REFERENCES}

Alexander, Jeffrey C. 2003. The Meanings of Social Life. A Cultural Sociology. N.Y.: Oxford University Press. http://dx.doi.org/10.1093/acprof:oso/9780195160840.001.000 1

Archer, M. 2007. From High Modernity to Nascent Globalization: The New Reflexive Imperative and Transformations of Civil Society. In: The $8^{\text {th }}$ European Sociological Association Conference. Conflict, Citizenship and Civil Society. Programme. $3^{\text {rd }}-6^{\text {th }}$ September 2007. Glasgow Caledonian University.

Baudrillard, J. 1983. Simulations. New York: Semiotext(e).
Bauman, Z. 2006. Liquid Fear. Cambridge: Polity Press.

Bauman, Z. 2009. Liquid Times. Living in an Age of Uncertainty. Cambridge: Polity Press.

Bauman, Z. 2011. 44 Letters from Liquid Modern World. Cambridge: Polity Press.

Beck, U. 2007. Risk Society Revisited: Theory, Politics and Research Programmes // The Risk Society and Beyond / B. Adam, U. Beck, J. van Loon (ed.). L.: Sage Publication.

Beck, U. 2010. World at Risk. Cambridge: Polity Press.

Bourdieu, P. 1990. In Other Words: Essays towards a Reflexive Sociology. Stanford, CA: Stanford University Press.

Caruth, Cathy, ed. 1995. Trauma: Explorations in Memory. Baltimore: Johns Hopkins University Press.

Eyerman, Ron. 2001. Cultural Trauma: Slavery and the Formation of African American Identity. New York: Cambridge University Press. http://dx.doi.org/10.1017/CBO9780511488788

Fukuyama, Francis. 1992. The End of History and the Last Man. N.Y.: Free Press.

Fuller, S. 2008. The New Sociological Imagination. London: Sage Publications.

Giddens, A. 1990. The Consequences of Modernity. Cambridge: Polity Press.

Gorshkov, M.K. 2011. Russian Society as it is (Experience of Sociological Diagnostics). Moscow: Russian Academy of Sciences. Institute of sociology.

Jameson, F. 1991. Postmodernism, or, The Cultural Logic of Late Capitalism. Durham: Duke University Press.

Mills, C.W. 1959. The Sociological Imagination. New York: Oxford University Press.

Neal, Arthur. 1998. National Trauma and Collective Memory. Armonk, NY: Sharpe.

Park, Robert. 1952. Human Communities: the City and Human Ecology. Glencoe, IL: Free Press.

Parsons, T. 1960. Structure and Process in Modern Societies. New York: Free Press

Popper, K. 1950. The Open Society and its Enemies. London: Routledge and Kegan Paul.

Prigogine, I. 1997. The End of Certainty. New York: Free Press.

Shaw, Clifford R. 1952. Brothers in Crime. Philadelphia: Albert Saifer.

Sztompka, P. 1991. Society in Action: A Theory of Social Becoming Cambridge: Polity Press.

Sztompka, P. 2000. Cultural Trauma. The Other Face of Social Change // European Journal of Social Theory, 2000. № 3(4).

Urry, J. 2003. Global Complexity. Cambridge: Polity Press.

Urry, J. 2005. The Complexities of the Global // Theory, Culture \& Society, 2005. Vol. 22 (5) http://dx.doi.org/10.1177/0263276405057201

Urry, J. 2011. Climate Change \& Society. Cambridge: Polity Press.

Yanitsky, O.N. 2010. Russian Environmentalism. The Yanitsky Reader. Moscow: Taus.

Received on 10-10-2012

Accepted on 13-12-2012

Published on 26-12-2012

DOI: http://dx.doi.org/10.6000/1929-4409.2012.01.21

(C) 2012 Sergey A. Kravchenko; Licensee Lifescience Global.

This is an open access article licensed under the terms of the Creative Commons Attribution Non-Commercial License (http://creativecommons.org/licenses/by-nc/3.0/) which permits unrestricted, non-commercial use, distribution and reproduction in any medium, provided the work is properly cited. 